\title{
The mediating role of perceived competence: testing a motivational sequence in university students
}

\section{El rol mediador de la competencia percibida: análisis de una secuencia motivacional en estudiantes universitarios}

Recibido: julio 7 de 2010 | Revisado: julio 29 de 2010 | Aceptado: septiembre 12 de 2010

\author{
JUAN L. NÚÑEZ ** \\ University of Las Palmas de Gran Canaria, Spain \\ José MARTín-ALBO **** \\ University of Zaragoza, Spain \\ AlberTo PAREDES **** \\ ÓlIVER RODRÍGUEZ \\ NOEMÍ CHIPANA \\ University of San Francisco Xavier de Chuquisaca, Bolivia
}

SICI: 1657-9267(201112)10:3<669:TMROPC > 2.3.TX;2-7

Para citar este artículo. Núñez, J. L., Martín-Albo, J., Paredes, A., Rodríguez, O. \& Chipana, N. (2011). The mediating role of perceived competence: testing a motivational sequence in university students. Universitas Psychologica, 10 (3), 669-680.

* Research article. Acknowledgments: This work was made possible thanks to funds provided by the University of Las Palmas de Gran Canaria (Spain) for Pre-competitive Research Projects, reference UNI2006/11.

** Departamento de Psicología y Sociología. C/ Santa Juana de Arco, 1. 35004 Las Palmas. E-mail: jnunez@dps.ulpgc.es

Research-ID: Nuñez, J. L., B-4513-2010

**** Facultad de Ciencias Sociales y Humanas. Ciudad escolar s/n.44003 Teruel.E-mail: jmartina@unizar. es

***** Calle Ovidio Céspedes s/n, entre calles La Paz y Avaroa. Edificio Carrera de Psicología. Sucre. Emails: cihued@yahoo.es, larostro@hotmail.com, cihued@yahoo.es

\section{A B S T R A C T}

In order to test the mediating role of perceived competence between each goal orientation (i.e. task and ego orientations) and intrinsic motivation in a motivational sequence in the context of university education, two models based on the cognitive evaluation theory and the achievement goal theory were tested with 276 Bolivian undergraduate students (138 males, $138 \mathrm{fe-}$ males), who completed Spanish versions of instruments designed to assess motivation, perceived competence, and positive emotions and interest. Two models were found with structural equation modeling techniques, one for ego orientation and one for task orientation. Results showed that perceived competence acts as a good mediator in the relation between ego orientation and intrinsic motivation, and as a partial mediator in the relation between task orientation and intrinsic motivation.

Key words authors

Self-determination, perceived competence, undergraduate students, intrinsic motivation, goal orientation.

Key words plus

Psychological tests, structural equation, quantitative research.

\section{RESUMEN}

Con el objetivo de probar el rol mediador de la competencia percibida entre cada una de las orientaciones de meta (ego y tarea) y la motivación intrínseca en una secuencia motivacional en el contexto universitario, se examinaron dos modelos basados en la teoría de la evaluación cognitiva y en la teoría de metas de logro. Las versiones en español de varias pruebas de motivación para evaluar la competencia percibida y las emociones positivas y el interés, fueron completadas por 276 (138 hombres y 138 mujeres) estudiantes universitarios bolivianos. Mediante la técnica de ecuaciones estructurales se verificaron dos modelos, uno para la orientación al ego y otro para la orientación a la tarea. Los resultados mostraron que la competencia percibida resulta un buen mediador en la relación entre orientación 
al ego y motivación intrínseca, y un mediador parcial en la relación entre orientación a la tarea y motivación intrínseca. Palabras clave autores

Autodeterminación, competencia percibida, estudiantes universitarios, motivación intrínseca, orientación de metas. Palabras clave descriptores

Pruebas psicológicas, ecuaciones estructurales, investigación cuantitativa.

One of the central problems when studying the variables involved in the improvement of intrinsic motivation and its consequences, lies in establishing how they are related to each other. In this sense, we speak of determinant variables, mediators, and consequences. In recent years, several studies within the theoretical frameworks of the Self-determination theory [SDT] (Deci \& Ryan, 1985) and the Achievement goal theory [AGT] (Ames, 1992) have shown that the basic psychological needs can act as a mediator between social variables (e.g. motivational climate, and the more self-determined motivation (e.g. intrinsic motivation); whereas other studies have established that both the social variables (e.g. motivational climate) and the personal variables (perception of satisfaction of basic psychological needs) act as determinants of intrinsic motivation at the same level. Therefore, we consider it relevant to test the mediating role of a personal variable like perceived competence with each goal orientation (i.e. task and ego orientations) and the self-determinated motivation in a motivational sequence in the context of university education.

The distinction between intrinsic motivation (IM) and extrinsic motivation (EM) has been one of the most useful approaches to understand students' motivation in the educational context (Csikszentmihalyi \& Nakamura, 1989; Deci \& Ryan, 1985, 1991, 2000; Ryan \& Deci, 2000). The SDT proposed by Deci and Ryan (1985) postulates that motivation is distributed along a continuum going from high levels of self-determination, where IM-characterized by satisfaction, interest, and pleasure when performing an activity-is located, to low levels of self-determination, where EM-defined by low levels of satisfaction and fun because the activity is only performed because of the presence of contingencies-is located.

Although many investigators consider IM a unitary and global construct, the hierarchical model of intrinsic and extrinsic motivation (HMIEM) proposed by Vallerand (1997) suggests that it is a multidimensional construct in which three types of motivation are distinguished: IM toward knowledge, which implies performing a behavior for the pleasure and satisfaction experienced when learning, exploring, or trying to understand new things; IM toward accomplishment, which has also been called task orientation or mastery oriented motivation, refers to performing an activity for the pleasure and satisfaction of attempting to achieve or master new contents; and IM toward stimulation, which occurs when a task is performed in order to experience the stimulating sensations associated with it, for the pleasure of exciting experiences.

From high to low levels of self-determination, SDT proposes various types of EM: Integrated regulation, where there is coherence between the behavior carried out and other structures within the ego; identified regulation, where the behavior is internalized and the individual considers it personally important; introjected regulation, where there is partial internalization, because the individual performs the activity to avoid feelings of guilt or anxiety; and external regulation, which occurs when the behavior is performed in the presence of external contingencies or rewards. Finally, amotivation is characterized by the absence of motivation and intention in the behavior (Deci \& Ryan, 1985, 1991, 2000).

The cognitive evaluation theory [CET] (Deci $\&$ Ryan, 1985) is a subtheory of SDT that specifies which determinants from the environment may or may not facilitate IM. This influence is mediated by three basic psychological needs that are innate, essential, and universal (Ryan \& Deci, 2000). These needs, denominated perceived autonomy, perceived competence, and relatedness, should be satisfied in order for people to achieve growth, integrity, development, and psychological wellbeing (Deci \& Ryan, 2000). Perceived autonomy is a characteristic that allows individuals to self- 
regulate and be the origin of their own behavior; perceived competence implies that the person feels effective when performing or developing a specific activity; and relatedness refers to the degree of a person's connection with significant others. In the academic setting, autonomy and perceived competence are two important mediators in the relation between the social environment and selfdetermined motivation (Guay \& Vallerand, 1997; Lavigne, Vallerand \& Miquelon, 2007; Vallerand, Fortier \& Guay, 1997).

Moreover, according to SDT, motivation is related to important consequences. Thus, as motivation becomes more self-determined, more positive consequences will ensue (Vallerand, 1997). Specifically, in the educational context, motivation has been related to consequences such as effort, positive emotions, psychological adjustment, quality of learning, concentration, satisfaction, and persistence (Fortier, Vallerand \& Guay, 1995; Gottfried, 1985, 1990; Grolnick \& Ryan, 1987; Guay \& Vallerand, 1997; Reeve, 2002; Ryan \& Connell, 1989; Standage, Duda \& Ntoumanis, 2005; Vallerand \& Bissonnette, 1992; Vallerand et al., 1997).

One of the theories which have explained the attainment of aims in contexts of achievement is the AGT (Ames, 1992; Nicholls, 1989). According to the AGT, people both assess their own competence and define the fulfilment of their success through two goal perspectives (i.e. task and ego orientations). Task-oriented individuals judge their competence by drawing a comparison between their own performances, whereas ego-oriented subjects assess their competence by contrasting their performance with that of others, and by showing a superior ability.

The two types of goal orientations are associated to different types of motivation. Task orientation is linked to IM, while ego orientation is linked to EM (Duda, Chi, Newton, Walling \& Catley, 1995; Spray, Wang, Biddle, Chatsizarantis \& Warburton, 2006; Wang, Chatzisarantis, Spray $\&$ Biddle, 2002). Ntoumanis (2001) showed that task orientation positively predicted all three types of IM. In an academic context, Butler (1987) esta- blished that task-oriented goals promote IM because they increase task persistence. Besides, Brunel (1999) found that ego orientation was positively associated to external regulation and introjected regulation in French undergraduate students.

Moreover, there is a relation between goal orientations and basic psychological needs. As regards this association, Ntoumanis (2001) states that high task orientation can fulfill one or more of the basic psychological needs, and these, at the same time, can increase self-determined motivation; in particular, task orientation can satisfy the need for competence. Duda (1992) holds that individuals with a high task orientation are less likely to feel incompetent than those with a high ego orientation. The reason for this is that the subjects with a high ego orientation assess their competence according to a normative criterium (e.g. being better than the others), which is harder to control. Goal orientation has also been revealed as a good predictor of basic psychological needs. Regarding this idea, Nicholls (1989) suggests that perceived competence moderates the effect of ego orientation in the motivational process; in this sense, for example, ego-oriented subjects who showed low perceived competence manifested a positive relation with lack of motivation, whereas those individuals with high perceived competence showed a positive relation with motivation.

In a recent study with female students, Wang and Liu (2007) found that perceived competence mediates the effects of achievement goals on enjoyment, being this an indicator of IM. Task orientation showed a positive and significant relation with perceived competence $(\beta=0.50 ; p<$ $0.05)$; likewise, ego orientation showed a positive and significant relation with perceived competence $(\beta=0.36 ; p<0.05)$; finally, perceived competence was a predictor of enjoyment $(\beta=0.37$; $p<$ 0.05). In this sense, Ntoumanis (2001) found that all self-determined motivation types (i.e. the three types of IM) were positively predicted by perceived competence.

Ferrer-Caja and Weiss $(2000,2002)$ propose a model in which they distinguish four elements: social factors, individual differences, IM, and 
motivational consequences. According to these authors, social factors (e.g. perceived motivational climate, teaching style) are directly related to individual factors (e.g. basic psychological needs, goal orientations) and indirectly related to IM and motivational consequences (e.g. effort, persistence). Goal orientations mediated the influence of social factors (e.g. perceived motivational climate, teaching style) on perceived competence; and the latter, at the same time, predicted IM. Thus, the social climate that a teacher provides (e.g. taskoriented climate) will influence the development of the orientation to this goal (task). This orientation acts as a mediator in the relationship between climate and the satisfaction of the need for perceived competence, which, in turn, will develop a greater intrinsic motivation. Results showed that task orientation was the variable which was most strongly related to IM; likewise, they indicated small direct negative paths linking ego orientation with IM. Task orientation had very small indirect paths through perceived competence.

To sum up, research has established that the role of the mediators between social factors and motivation - considering basic psychological needs and goal orientations as such mediators - is relevant to the explanation of IM, although there is little agreement about the character of their relations as, in some cases, they are all found to be at the same level (Ferrer-Caja \& Weiss, 2002), and, in other cases, goal orientations have been found to predict basic psychological needs (Ntoumanis, 2001; Wang $\&$ Liu, 2007). These previous studies have not featured any analysis of the mediating role of basic psychological needs between goal orientations and IM, because all of them have considered these needs as antecedents of the goal orientations (e.g. social factors). Besides, as Hardy $(1997,1998)$ argues, research about the orthogonality of goal orientations has not been conclusive, and this aspect could have an influence on the kind of relation with other variables. Moreover, although there is evidence to suggest that ego-oriented individuals are more fragile from a motivational point of view when their perceived competence is low (Cury, Biddle, Sarrazin \& Famose, 1997; Duda \& Hall, 2001), this appears not to be invariably (Biddle, Wang, Chatzisarantis \& Spray, 2003). Therefore, we consider it necessary to test the mediating role of perceived competence with each goal orientation (i.e. task and ego orientations) and IM in a motivational sequence in the context of university education.

\section{Method}

\section{Objectives and hypotheses}

The main purpose of this study is to test the mediating role of perceived competence with each goal orientation (i.e. task and ego orientations) and IM in a motivational sequence in the context of university education. Because it is a descriptive study comparing two models derived from the same theory, the hypotheses are the models themselves.

\section{Participants}

Took part in this study 276 students from the Faculty of Humanities of the University of San Francisco Xavier of Chuquisaca de Sucre (Bolivia). They were 138 men and 138 women, with a mean age of 20.7 years $(S D=3.31)$. Of these participants, 67 students were registered in a degree in Pedagogy, 71 in Tourism, 56 in Languages, and 82 in Psychology. The method of cluster sampling was used, with the class as the sampling unit, after randomly selecting the class groups that comprise the sample of the study.

\section{Variables and Measures}

In this study, five latent variables and 11 observed variables were used: Firstly, ego orientation, which featured two indicators, each corresponding to the average score of four items (i.e. ego1, and ego2); secondly, task orientation, which included two indicators, each representing the average score of four items (i.e. task1, and task2); thirdly, perceived competence, which included two indicators, each amounting to the average score of three items (i.e. comp1, and comp2); fourthly, IM, which consisted of three indicators corresponding to the subscales 
of the EME (i.e. IM know, IM accomplish, and IM stimulation); and finally, consequences, which included two indicators (interest, and positive emotions) corresponding to the subscales of the Perceived Autonomy in Life Domains Scale (Blais \& Vallerand, 1991).

In order to measure the participants' tendency towards the task, and ego, we used the two subscales of the Spanish version of the Motivational Orientation Scale (Castillo, Balaguer \& Duda, 2001). Each subscale was measured by eight items. Participants rated their responses on a 5-point Likert-type rating scale, ranging from 1 (strongly disagree) to 5 (strongly agree). The alpha coefficients were 0.78 for task orientation and 0.81 for ego orientation.

The perceived competence of the students was assessed by means of six items taken from a Spanish version of the Basic Need Satisfaction at Work Scale as adapted to the academic setting, which has been used in previous studies. The dimension was rated on a 7-point Likert-type scale ranging from 1 (not at all true) to 7 (very true). The alpha for the perceived competence dimension was 0.73 .

To measure the latent variable IM, we used three dimensions from the Spanish version of the Academic Motivation Scale (Núñez, Martín-Albo $\&$ Navarro, 2005), which measure IM toward accomplishment, IM toward knowledge, and IM toward stimulation, each one comprising 4 items. Participants rate their degree of agreement on a 7-point Likert-type scale ranging from 1 (does not correspond at all) to 7 (corresponds exactly). The global alpha for the variable IM was 0.88 .

The dimensions of positive emotions and interest from an adapted Spanish version of the Perceived Autonomy in Life Domains Scale (Blais \& Vallerand, 1991) were used to measure the latent variable consequences. These two dimensions have four items each and participants rate their degree of agreement on a 7-point Likert-type scale ranging from 1 (strongly disagree) to 7 (strongly agree). The global alpha for the variable consequences was 0.85 .

\section{Procedure}

After selecting the sample groups to be used, we contacted the directors of the degrees to explain to them the purpose of the study and to set up with them and the teachers of the classes in the selected classrooms the most suitable times to administer the instruments. We also explained the goal of the study to the students, informing them of the voluntary nature of their participation and the confidentiality of their responses, requesting their collaboration, and urging them to respond sincerely and honestly. All instruments were applied in the classroom on the same day, before the beginning of the classes. The application time was 20 minutes.

\section{Results}

Structural equation modeling (SEM) was used because this kind of analysis allows us to determine the relations established between the exogenous and endogenous variables.

\section{Descriptive Statistics}

The descriptive statistics (means, standard deviation, skewness, and kurtosis) of the variables of this study are shown in Table 1 . As can be seen, all the skewness values are below 2, and the kurtosis values are below 7 , which indicates similarity to the normal curve, as recommended by Curran, West, and Finch (1996). The Mardia's coefficient was 26.83. On the basis of these results, we used the maximum likelihood estimation, as, within the context of structural equations, it is reasonably robust even if multivariate normality is not fulfilled (West, Finch \& Curran, 1995). Likewise, we have used a bootstrap of 200 samples.

\section{TABLE 1}

Descriptive statistics of the observed variables

\begin{tabular}{lcccc}
\hline & M & SD & Skewness & Kurtosis \\
\hline Task 1 & 3.77 & 0.65 & -0.66 & 1.06 \\
Task 2 & 4.16 & 0.64 & -1.31 & 4.14
\end{tabular}




\begin{tabular}{lcccc}
\hline & M & SD & Skewness & Kurtosis \\
\hline Ego 1 & 3.01 & 0.75 & 0.22 & -0.12 \\
Ego 2 & 2.50 & 0.75 & 0.27 & 0.07 \\
Competence 1 & 4.68 & 1.14 & 0.01 & -0.18 \\
Competence 2 & 4.54 & 1.22 & -0.07 & -0.25 \\
IM toward Ac- & 5.31 & 1.10 & -0.74 & 0.65 \\
complishment & & & & \\
IM toward & 5.65 & 0.96 & -0.72 & 0.57 \\
Knowledge & & & & \\
IM toward & 4.42 & 1.18 & -0.11 & -0.13 \\
Stimulation & & & & \\
Positive & 5.11 & 1.16 & -0.68 & 0.81 \\
Emotions & & & & 0.12 \\
Interest & 5.66 & 0.90 & -0.72 & 0.12 \\
\hline
\end{tabular}

Source: Own work.

The bivariate correlation analysis (see Table 2) showed positive and significant correlations between the indicators under observation, except for the correlations between positive emotions and ego2, and interest and ego2. The correlations which were the highest and which were significant $(p<0.01)$ occurred between the indicators which constitute the same latent variable. The lowest correlation arose between the two ego indicators, and the positive emotions and interest indicators.

\section{Structural equation modeling}

To test the mediating role of perceived competence between goal orientations (i.e. ego and task orientations) and IM, two structural equation analyses were carried out, since, as scientific literature suggests, the two goal orientations may be orthogonal. The models which were tested were identified, since every latent variable had two indicators at least (McDonald \& Ho, 2002). The sequence of the first tested model was ego orientation $\rightarrow$ perceived competence $\rightarrow$ IM $\rightarrow$ consequences; and the sequence of the second tested model was task orientation $\rightarrow$ perceived competence $\rightarrow$ IM $\rightarrow$ consequences.

The mediating role of perceived competence between ego orientation and IM

In order to study the mediating role of the variables, we followed the recommendations of Baron

\section{TABLE 2}

Bivariate correlations among all variables

\begin{tabular}{|c|c|c|c|c|c|c|c|c|c|c|c|}
\hline Variables & 1 & 2 & 3 & 4 & 5 & 6 & 7 & 8 & 9 & 10 & 11 \\
\hline 1. Task 1 & & $0.62^{* * *}$ & $0.47^{* *}$ & $0.24^{* * *}$ & $0.39^{* * *}$ & $0.37^{* * *}$ & $0.40^{* * *}$ & $0.31^{* * *}$ & $0.24^{* * *}$ & $0.28^{* *}$ & $0.28^{* *}$ \\
\hline 2. Task 2 & & & $0.21^{* *}$ & $0.15^{*}$ & $0.32^{* * *}$ & $0.39^{* *}$ & $0.37^{* * *}$ & $0.38^{* * *}$ & $0.28^{* * *}$ & $0.26^{* *}$ & $0.27^{* * *}$ \\
\hline 3. Ego 1 & & & & $0.59^{* *}$ & $0.25^{* *}$ & $0.29^{* *}$ & $0.23^{* *}$ & $0.18^{* *}$ & $0.17^{* *}$ & $0.18^{* *}$ & $0.12^{*}$ \\
\hline 4. Ego 2 & & & & & $0.12^{*}$ & $0.22^{* *}$ & $0.14^{*}$ & $0.14^{*}$ & $0.19^{* *}$ & 0.10 & 0.01 \\
\hline 5. Competence 1 & & & & & & $0.59^{* *}$ & $0.51^{* *}$ & $0.37^{* *}$ & $0.38^{* *}$ & $0.48^{* *}$ & $0.46^{* * *}$ \\
\hline 6. Competence 2 & & & & & & & $0.48^{* * *}$ & $0.39^{* *}$ & $0.36^{* *}$ & $0.40^{* *}$ & $0.37^{* * *}$ \\
\hline 7. IM toward Accomplishment & & & & & & & & $0.62^{* *}$ & $0.51^{* * *}$ & $0.56^{* *}$ & $0.56^{* *}$ \\
\hline 8. IM toward Knowledge & & & & & & & & & $0.57^{* *}$ & $0.45^{* *}$ & $0.50^{* *}$ \\
\hline 9. IM toward Stimulation & & & & & & & & & & $0.32^{* *}$ & $0.32^{* * *}$ \\
\hline 10. Positive Emotions & & & & & & & & & & & $0.74^{* * *}$ \\
\hline 11. Interest & & & & & & & & & & & \\
\hline
\end{tabular}

Source: Own work. 
and Kenny (1986). The tested model suggests that perceived competence acts as a mediator between ego orientation and IM.

To test the measurement model, a CFA was carried out by way of an oblique model composed of all the latent variables which were part of the theoretical structural model. Given that Mardia's coefficient was high (14.21), the fit of the model was tested by means of the maximum likelihood method, together with the bootstrapping standard procedure with 500 resampling runs. This procedure provides an average of the estimates obtained from bootstrap samples and its standard error. In addition, the bootstrapping procedure compares estimated values without bootstrapping with averages obtained from bootstrap samples, indicating the level of bias. Confidence intervals (i.e. differences between the highest and the lowest estimated values from the different bootstrap samples) of the regression weights and standardised regression weights showed that estimated values were significantly different from zero, so as to consider that the lack of normality does not affect the estimates (Byrne, 2001).

In view of the proposed cutoff criteria, the results of the measurement model were acceptable; besides, the bootstrapping confidence intervals were significantly different from zero, and, as a consequence, the estimated parameters were robust. In particular, the fit indices were as follows: $\mathrm{CFI}$ $=0.97 ;$ IFI $=0.97 ;$ RMSEA $=0.07(90 \% \mathrm{CI}=$ $0.04-0.09) ; \mathrm{SRMR}=0.04$. All parameters were significant $(p<0.01)$.

The results from the SEM were the following: $\mathrm{CFI}=0.97$; IFI $=0.97$ RMSEA $=0.07(90 \%$ $\mathrm{CI}=0.05$ - 0.09); SRMR $=0.04$. All parameters were significant $(p<0.01)$. In order to test the mediating role of perceived competence, we followed the suggestions of Baron and Kenny (1986), and observed four steps. First of all, we proved the direct effect of ego orientation (predictor) on IM (outcome), and this showed a positive and significant relation $(\beta=0.28 ; p<0.05)$. Secondly, we demonstrated that ego orientation (predictor) had a relation with perceived competence (mediator), which was positive and significant $(\beta=0.37 ; p<$
0.05). The third step involved demonstrating that there is a relation between perceived competence (mediator) and IM (outcome), which was positive and significant $(\beta=0.73 ; p<0.05)$. Finally, we showed that the relation between ego orientation and IM is significantly reduced when the mediator (perceived competence) is incorporated. Results showed that the direct effect of ego orientation on IM decreased when the perceived competence was added, even though its value was far from zero $(\beta$ $=0.01 ; p>0.05)$. These results demonstrate that perceived competence acts as a good mediator in the relation between ego orientation and IM. The explained variances of perceived competence, $\mathrm{IM}$, and consequences were $13 \%, 58 \%$, and 55 $\%$ respectively. The power of the model was 0.64 $(\varepsilon=0.01)$.

\section{The mediating role of perceived competence between task orientation and IM}

The fit indices for the measurement model were as follows: $\mathrm{CFI}=0.98$; IFI $=0.98$; $\mathrm{RMSEA}=$ $0.07(90 \% \mathrm{CI}=0.04-0.09)$; $\mathrm{SRMR}=0.03$. All parameters were significant $(p<0.01)$. Mardia's coefficient was 23.75 , and the bootstrapping confidence intervals were significantly different from zero, and, as a consequence, the estimated parameters were robust.

With regard to the SEM, the indices were as follows: $\mathrm{CFI}=0.97 ; \mathrm{IFI}=0.97 ; \mathrm{RMSEA}=0.07(90$ $\% \mathrm{CI}=0.05-0.09) ; \mathrm{SRMR}=0.04$. All parameters were significant $(p<0.01)$, and the bootstrapping confidence intervals were different from zero, thus indicating that the parameters were robust.

The four steps which were taken in order to analyse the mediating role of perceived competence between task orientation (predictor) and IM (outcome) demonstrated that the relation between task orientation and IM (step 1) was positive and significant $(\beta=0.55 ; p<0.05)$. Likewise, the relation between task orientation and perceived competence (step 2) was positive and significant $(\beta=0.65 ; p<0.05)$. The relation between perceived competence and IM (step 3 ) was also positive and significant $(\beta=0.76 ; p<0.05)$. Finally, when 
FIGURE 1

Structural equation model that analyzes the relations among ego orientation, perceived competence, intrinsic motivation (IM) and consequences. All parameters are standardized and significant at $p<0.01$

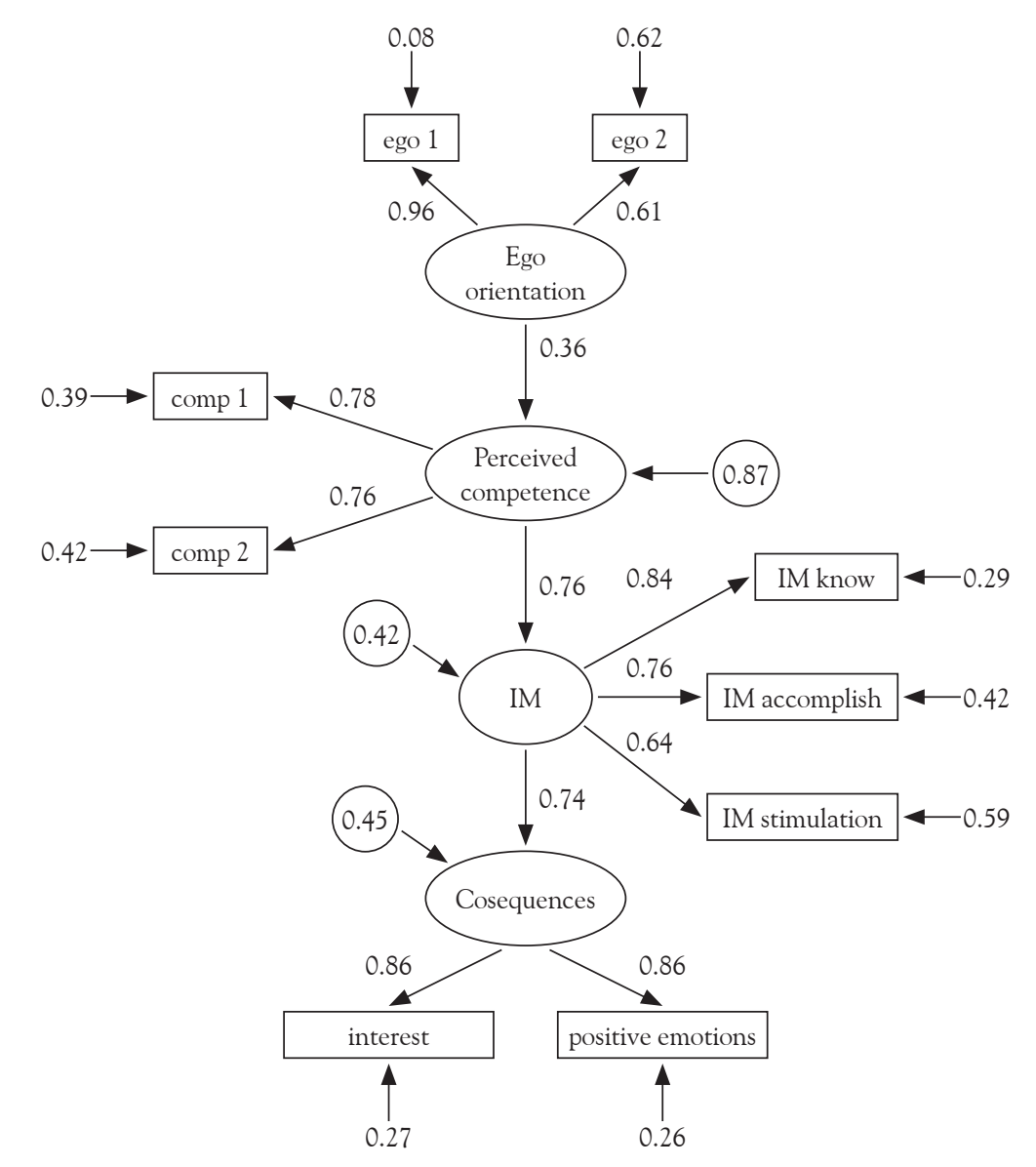

Source: Own work.

perceived competence was incorporated, the relation between task orientation and IM decreased even though it remained significant $(\beta=0.20$; $p$ $<0.05)$. In short, the perceived competence is a partial mediator in the relation between task orientation and IM. The explained variances of perceived competence, IM, and consequences were $37 \%, 60 \%$, and $55 \%$, respectively. The power of the model was $0.64(\varepsilon=0.01)$.

\section{Discussion}

The purpose of this study was to test the mediating role of perceived competence between each goal orientation (i.e. task and ego orientations) and
IM in a motivational sequence in the context of university education. These relations have been examined by testing two models based on CET (Deci \& Ryan, 1985), and AGT (Ames, 1992; Nicholls, 1989). In general, results showed that perceived competence mediates the effects of goal orientations on IM, as claimed by Nicholls (1989) and in accordance with the results obtained by Wang and Liu (2007).

With respect to the mediation of perceived competence between ego orientation and IM, results showed that perceived competence is a good mediator between these variables. In particular, ego orientation was found to be positively and significantly related to perceived competence, in 
Figure 2

Structural equation model that analyzes the relations among task orientation, perceived competence, intrinsic motivation (IM) and consequences. All parameters are standardized and significant at $p<0.01$

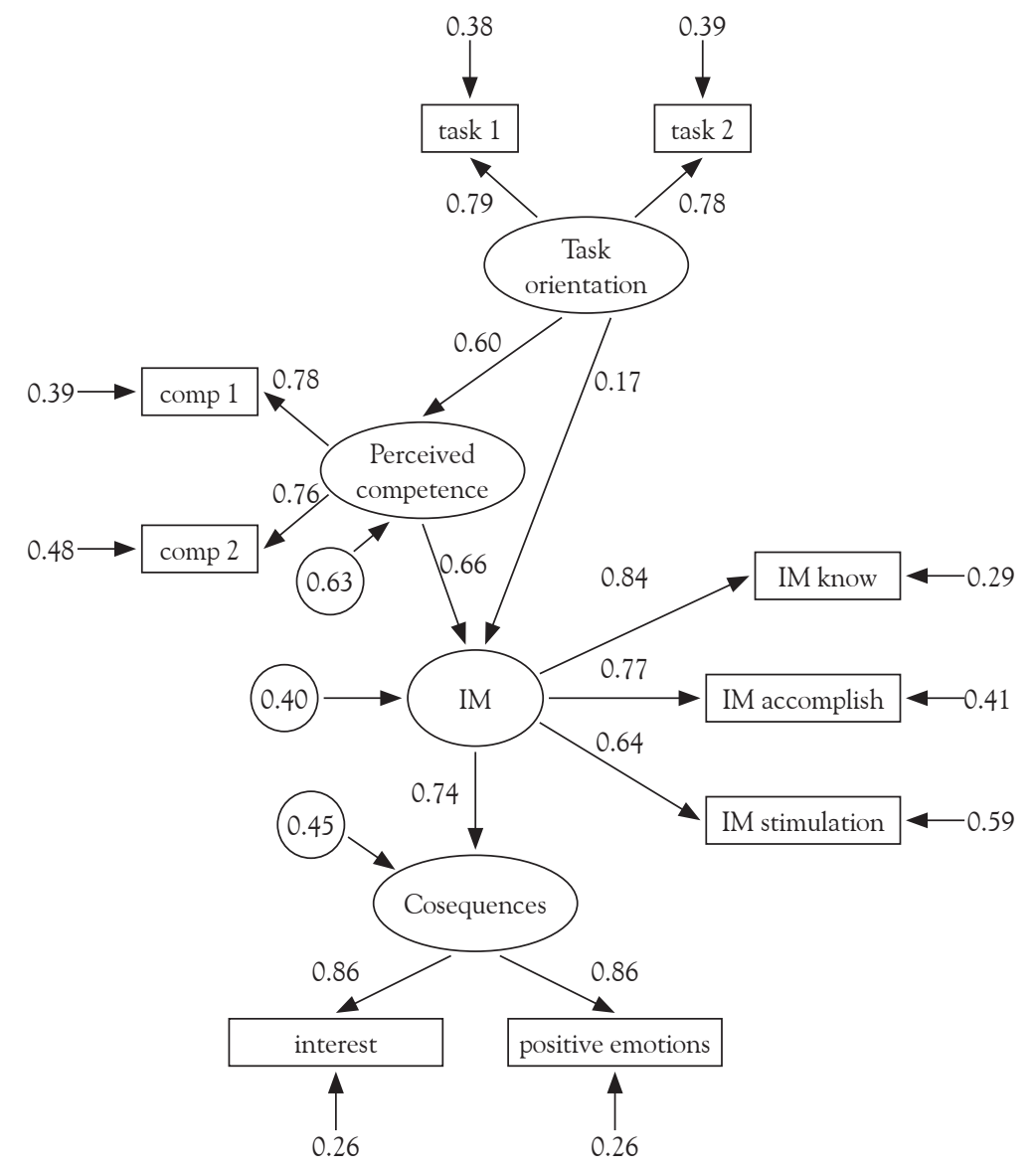

Source: Own work.

conformity with the study by Wang and Liu (2007); perceived competence was related in a positive and significant way with IM, a result which was in agreement with the theoretical assumptions proposed by CET (Deci \& Ryan, 1985); likewise, ego orientation showed a positive and significant relation with IM. This result goes against the predictions by AGT (Ames, 1992; Nicholls, 1989), but agrees with the study by Ntoumanis (2001), where IM toward stimulation was positively predicted by ego orientation. An explanation for this could be that, when obtaining good academic results as opposed to those of others, students experience positive sensations and excitement, and they feel that they have an excellent command of the subject and that they have learnt more than their fellow students. Finally, by incorporating perceived competence as mediator between ego orientation and IM, the relation between ego orientation and IM is next to zero, and this implies that perceived competence mediates between both variables; this result is in agreement with Nicholls (1989) when he claims that the individuals who have a high perceived competence and who do not lack confidence in themselves when comparing to others (i.e. ego oriented individuals) show a positive relation with motivation. In this sense, from the point of view of AGT (Ames, 1992; Nicholls, 1989), perceived competence may play a mediating role only when it is analysed in a comparative 
context (i.e. ego orientation); and this is why the encouragement of perceived competence, namely the development of a sensation of being effective when performing or developing a specific activity, is a key factor for ego oriented students to show a more self determined motivation.

Regarding the mediating role of perceived competence between task orientation and IM, results have established that perceived competence is a partial mediator in the relation between task orientation and IM. These findings are in agreement with the results obtained by Ferrer-Caja and Weiss (2000), in two samples, one with male students, and another with female students, and with those reached by Ntoumanis (2001), who states that task orientation may satisfy the basic psychological need of perceived competence. Learning goals are salient when individuals are concerned with self-referenced mastery of tasks and increasing their competence (Biddle et al, 2003). The direct effect of task orientation on IM is consistent with the assumptions of AGT (Ames, 1992; Nicholls, 1989), as proved by a number of studies (Duda et al., 1995; Spray et al., 2006; Wang et al., 2002). Besides, as suggested by SDT (Deci \& Ryan, 1985), the basic psychological needs (i.e. perceived competence) have a direct and independent influence on IM. In other words, the perceived competence of students is not a determinant mediator between task orientation and IM, and, as a consequence, in order to encourage IM in academic contexts, the focus could be on those conditions which favour task orientation.

Likewise, the results obtained in the two tested models conform to the postulates of SDT (Deci \& Ryan, 1985), according to which perceived competence has a direct and positive influence on IM; and IM, at the same time, implies positive consequences (i.e. interest and positive emotions). These results are similar to those reached by FerrerCaja and Weiss $(2000,2002)$.

In general, our results support the idea advanced by Ryan (1982) and Butler (1989) of considering the goal orientations of individuals together with their perceived competence when examining IM.
However, this study presents some limitations which should be taken into account. Firstly, the models which have been studied used a sample of university students, and it would be relevant to perform an analysis of invariance as a function of variables that may affect the results, such as gender. Secondly, regarding external validity, the participants of this study were university students; therefore, we cannot generalize the results to the general population. Thirdly, future research should consider other types of ego orientation (i.e. avoidance and approximation) which, in the educational context, have been associated to different motivational antecedents and consequences (Elliot, 1999). Fourthly, future studies should also analyze the influence which goal orientations and perceived competence have on the several types of EM and their possible consequences. Lastly, as this study was carried out at a contextual level, it would be interesting to verify the mediating role of perceived competence at other levels of generality (i.e. global and situational levels), as proposed by HMIEM (Vallerand, 1997).

To sum up, and considering the purpose of this study, we can state that individual factors (i.e. goal orientations and perceived competence) affect the IM of university students. Thus, perceived competence must be considered a mediator between the effects of goal orientations on IM when planning an intervention to increase IM and the consequences explained by IM.

\section{References}

Ames, C. (1992). Classrooms: Goals, structures, and student motivation. Journal of Educational Psychology, 84 (3), 261-271.

Baron, R. M. \& Kenny, D. A. (1986). The moderatormediator variable distinction in social psychological research: Conceptual, strategic, and statistical considerations. Journal of Personality and Social Psychology, 5, 1173-1182.

Biddle, S., Wang, C. K., Chatzisarantis, N. \& Spray, C. (2003). Motivation for physical activity in young people: Entity and incremental beliefs about 
athletic ability. Journal of Sports Sciences, 21, 973 989.

Blais, M. R. \& Vallerand, R. J. (1991). Construction et validation de l'Échelle des Perceptions d'Autonomie dans les Domaines de Vie. Université du Québec à Montréal, Canada. Unpublished manuscript.

Brunel, P. (1999). Relationship between achievement goal orientations and perceived motivational climate on intrinsic motivation. Scandinavian Journal of Medicine and Science in Sports, 9, 365-374.

Butler, R. (1987). Task-involving and ego-involving properties of evaluation: Effects of difference feedback conditions on motivational perceptions, interest, and performance. Journal of Educational Psychology, 79, 474-482.

Butler, R. (1989). Interest in the task and interest in peers' work in competitive and non competitive conditions: A developmental study. Child Development, 60, 562-570.

Byrne, B. M. (2001). Structural equation modeling with AMOS: Basic concepts, applications, and programming. Mahwah, NJ: Lawrence Erlbaum.

Castillo, I., Balaguer, I. \& Duda, J. L. (2001). Perspectivas de meta de los adolescentes en el contexto académico. Psicothema, 13 (1), 79-86.

Csikszentmihalyi, M. \& Nakamura, J. (1989). The dynamics of intrinsic motivation: A study of adolescents. In C. Ames \& R. Ames (Eds.), Research on motivation in education. Goals and cognitions (Vol. 3, pp. 45-71). New York: Academic Press.

Curran, P. J., West, S. G. \& Finch, J. F. (1996). The robustness of test statistics to nonnormality and specification error in confirmatory factor analysis. Psychological Methods, 1 (1), 16-29.

Cury, F., Biddle, S., Sarrazin, P. \& Famose, J. P. (1997). Achievement goals and perceived ability predict investment in learning a sport task. British Journal of Educational Psychology, 67, 292-309.

Deci, E. L. \& Ryan, R. M. (1985). Intrinsic motivation and self-determination in human behavior. New York: Plenum Press.

Deci, E. L. \& Ryan, R. M. (1991). A motivational approach to self: Integration in personality. In R. Dienstbier (Ed.), Nebraska symposium on motivation: Perspectives on motivation (Vol. 38, pp. 237 288). Lincoln, NE: University of Nebraska Press.
Deci, E. L. \& Ryan, R. M. (2000). The "what" and "why" of goal pursuits: Human needs and the selfdetermination of behavior. Psychological Inquiry, 11 (4), 227-268.

Duda, J. L. (1992). Motivation in sport settings: A goal perspective approach. In G. C. Roberts (Ed.), Motivation in sport and exercise (pp. 57-91). Champaign, IL: Human Kinetics.

Duda, J. L., Chi, L., Newton, M., Walling, M. \& Catley, D. (1995). Task and ego orientation and intrinsic motivation in sport. International Journal of Sport Psychology, 26, 40-63.

Duda, J. L. \& Hall, H. (2001). Achievement goal theory in sport: Recent extensions and future directions. In R. N. Singer, H. A. Hausenblas \& C. M. Janelle (Eds.), Handbook of sport psychology (pp. 417-443). New York: Wiley.

Elliot, A. J. (1999). Approach and avoidance motivation and achievement goals. Educational Psychologist, 34, 169-189.

Ferrer-Caja, E. \& Weiss, M. R. (2000). Predictors of intrinsic motivation among adolescent students in physical education. Research Quarterly for Exercise and Sport, 71 (3), 267-279.

Ferrer-Caja, E. \& Weiss, M. R. (2002). Cross-validation of a model of intrinsic motivation with students enrolled in high school elective courses. The Journal of Experimental Education, 71 (1), 41-65.

Fortier, M. S., Vallerand, R. J. \& Guay, F. (1995). Academic motivation and school performance: Toward a structural model. Contemporary Educational Psychology, 20, 257-274.

Gottfried, A. E. (1985). Academic intrinsic motivation in elementary and junior high school students. Journal of Educational Psychology, 77, 631-645.

Gottfried, A. E. (1990). Academic intrinsic motivation in young elementary school children. Journal of Educational Psychology, 82, 525-538.

Grolnick, W. S. \& Ryan, R. M. (1987). Autonomy in children's learning: An experimental and individual difference investigation. Journal of Personality and Social Psychology, 52, 890-898.

Guay, F. \& Vallerand, R. J. (1997). Social context, students' motivation, and academic achievement: Toward a process model. Social Psychology of Education, 1, 211-233. 
Hardy, L. (1997). The Coleman Roberts Griffith address: Three myths about applied consultancy work. Journal of Applied Sport Psychology, 9, 277 294.

Hardy, L. (1998). Responses to the reactants on three myths in applied consultancy work. Journal of Applied Sport Psychology, 10, 212-219.

Lavigne, G. L., Vallerand, R. J. \& Miquelon, P. (2007). A motivational model of persistence in science education: A self-determination theory approach. European Journal of Psychology of Education, 22 (3), 351-369.

McDonald, R. P. \& Ho, R. M. (2002). Principles and practice in reporting structural equation analyses. Psychological Methods, 7, 64-82.

Nicholls, J. (1989). The competitive ethos and democratic education. Cambridge, MA: Harvard University Press.

Ntoumanis, N. (2001). Empirical links between achievement goal theory and self-determination theory in sport. Journal of Sports Sciences, 19, 397-409.

Núñez, J. L., Martín-Albo, J. \& Navarro, J. G. (2005). Validación de la versión española de l'Échelle de Motivation en Éducation. Psicothema, 17 (2), 344-349.

Reeve, J. (2002). Self-determination theory applied to educational settings. In E. L. Deci \& R. M. Ryan (Eds.), Handbook of self-determination research (pp. 183-203). Rochester, NY: University of Rochester Press.

Ryan, R. M. (1982). Control and information in the intrapersonal sphere: An extension of cognitive evaluation theory. Journal of Personality and Social Psychology, 43, 450-461.

Ryan, R. M. \& Connell, J. P. (1989). Perceived locus of causality and internalization: Examining reasons for acting in two domains. Journal of Personality and Social Psychology, 57, 749-761.

Ryan, R. M. \& Deci, E. L. (2000). Intrinsic and extrinsic motivations: Classic definitions and new directions. Contemporary Educational Psychology, 25, 54-67.

Spray, C. M., Wang, C. K., Biddle, S. J., Chatsizarantis, N. L. \& Warburton, V.E. (2006). An experimental test of self-theories of ability in youth sport. Psychology of Sport and Exercise, 7, 255-267.

Standage, M., Duda, J. L. \& Ntoumanis, N. (2005). A test of self-determination theory in school physical education. British Journal of Educational Psychology, 75, 411-433.

Vallerand, R. J. (1997). Toward a hierarchical model of intrinsic and extrinsic motivation. In M. Zanna (Ed.), Advances in experimental social psychology (Vol. 29, pp. 271-360). Toronto: Academic.

Vallerand, R. J. \& Bissonnette, R. (1992). Intrinsic, extrinsic, and amotivational styles as predictors of behavior: A prospective study. Journal of Personality, 60, 599-620.

Vallerand, R. J., Fortier, M. S. \& Guay, F. (1997). Selfdetermination and persistence in a real-life setting: Toward a motivational model of high school dropout. Journal of Personality and Social Psychology, 72 (5), 1161-1176.

Wang, C. K., Chatzisarantis, N. I., Spray, C. M. \& Biddle, S. J. (2002). Achievement goals profiles in school physical education: Differences in selfdetermination, sport ability beliefs, and physical activity. British Journal of Educational Psychology, 72, 433-445.

Wang, C. K. \& Liu, W. C. (2007). Promoting enjoyment in girls' physical education: The impact of goals, beliefs, and self-determination. European Physical Education Review, 13 (2), 145-164.

West, S. G., Finch, J. F. \& Curran, P. J. (1995). Structural equation models with non-normal variables. Problems and remedies. In R. H. Hoyle (Ed.), Structural equation modeling: Concepts, issues and applications (pp. 56-75). Thousand Oaks, CA: Sage. 